\title{
Properties of Lightweight Matrix according to Different Types of Alkali Stimulants
}

\author{
Won-Jong, Kim, Su-Jeong, Pyeon, Ha-Young, Song, Sang-Soo, Lee
}

\begin{abstract}
Recently, lightweight wall systems have been used mainly due to the appearance of flexible buildings, but EPS, which is flammable, is the main material. The damage caused by toxic gas in fire is recognized as a problem.

$\mathrm{NaOH}, \mathrm{KOH}$ and $\mathrm{Ca}(\mathrm{OH}) 2$ were used as alkali stimulants and the properties of the matrix were evaluated according to the addition ratio of alkali stimulants. The addition of an alkali stimulant increases the $\mathrm{pH}$ and increases the alkali activity of the blast furnace slag, thereby changing the performance of the matrix. When $\mathrm{NaOH}$ and $\mathrm{KOH}$ are used as alkali stimulants, the density of the cured product is low and the incidence of the internal void of the cured product is high. When $\mathrm{Ca}(\mathrm{OH}) 2$ is used as an alkali stimulant, it shows the best performance when measuring $\mathrm{pH}$, setting time, and strength. This seems to be due to the ionization degree of the $(\mathrm{OH})$ group. However, the incidence of voids was the lowest. When $\mathrm{NaOH}$ and $\mathrm{KOH}$ are used as alkali stimulants, the density of the cured product is low and the incidence of the internal void of the cured product is high. When $\mathrm{Ca}(\mathrm{OH}) 2$ is used as an alkali stimulant, it shows the best performance when measuring $\mathrm{pH}$, setting time, and strength. This seems to be due to the ionization degree of the $(\mathrm{OH})$ group. However, the incidence of voids was the lowest.
\end{abstract}

Keywords : Lightweight matrix, Alkali stimulants, $p H$, Setting time, Strength, Density, Porosity

\section{INTRODUCTION}

$\mathrm{R}$ Recently, a fire occurred at the Daegu food factory was able to suppress the fire after three factories were burnt down. The factory where the fire occurred is a sandwich panel structure with both sides of iron plate and middle insulation panel. Insulation materials used for core materials include EPS, polyurethane, glass wool, and mineral wool. The sandwich panel structure is apparently covered with an iron plate, which is thought to have properties such as fire resistance, but the EPS of the core material is burned quickly in a fire. In case of fire, it is difficult to grasp the accurate ignition point inside due to the iron plate surrounding the outside, and the position of the fire and the degree of combustion can not be easily grasped. As the inner core is burned, the steel plate supporting the load of the building is instantly collapsed by the heat of combustion and the load. It

Revised Manuscript Received on July 22, 2019.

* Correspondence Author

Won-Jong, Kim*, Dept of architecture Engineering, HanBat National Univercity, Daejeon, Korea. Email:kojsy@yahoo.co.kr.

Su-Jeong, Pyeon, Dept of architecture Engineering, HanBat National Univercity, Daejeon, Korea. Email:pyeonsj@naver.com.

Ha-Young, Song, Dept of architecture Engineering, HanBat National Univercity, Daejeon, Korea. Email:hysong @ hanbat.ac.kr

Sang-Soo, Lee, Dept of architecture Engineering, HanBat National Univercity, Daejeon, Korea. Email:sslee111@hanbat.ac.kr is difficult to penetrate fire extinguishing agent or fire water due to the iron plate surrounding the core material, so it is difficult to suppress the fire due to the strength of the sandwich panel when the iron plate is attempted to be destroyed. Sandwich panels also have a faster vertical fire spread than horizontal fire spreads. Due to the frequent occurrence of large fires such as building partition walls and sandwich panels using combustible materials due to fire growth, the Ministry of Land, Transport and Maritime Affairs enacted the fire safety standards of buildings through amendment of the Enforcement Decree of the Building Act, From December 29, a plan to enforce the construction method has been implemented, which requires the use of fireproof materials that have passed the fire resistance test standards, as well as the interior finishing materials of buildings. The implementation of these proposals requires improvement of fire resistance and fire resistance in wall systems that occupy most of existing buildings. As the use of lightweight wall system has been increasing due to the development of domestic construction technology, EPS is used as a main material. Therefore, it is recognized that damage caused by toxic gas is a problem in fire. As a result, the need for research on core materials using inorganic materials has been attracting attention in order to secure fire safety for lightweight composite panel core materials mainly using organic materials[1]-[3].

\section{EXPERIMENTAL PLAN AND MATERIALS}

\section{A. Experimental Plan}

This study was planned based on the research of lightweight matrix by Kim Yoon-mi in 2015(4). This study was carried out to investigate the properties of matrix and matrix according to the types of alkali stimulants used in making lightweight matrix. Experimental factors and levels are shown in Table 1, and lightweight matrix was produced by using blast furnace slag and paper ash.

\section{B. Blast furnace slag}

Blast furnace slag fine powder is defined as KS F 2563 "Blast furnace slag fine powder for concrete", which is obtained by dry grinding blast furnace slag or adding gypsum thereto. Also, in the production method, the blast furnace slag fine powder is produced by dry grinding blast furnace slag. When gypsum is added, an appropriate amount of gypsum is added to the blast furnace slag to be mixed and ground, or the blast furnace slag and gypsum are separately pulverized, and they are mixed at a predetermined ratio and sufficiently mixed. 
In case of using grinding aid to increase grinding efficiency at grinding, it should be confirmed that it does not adversely affect the quality of blast furnace slag fine powder, and the use amount thereof is specified to be $1 \%$ or less of the blast furnace slag fine powder mass[5]-[8].

\section{Paper ash}

Typical paper sludge consists of organic and inorganic components. Organic components are pulp residue, screen residue, cleaner residue, etc. in the process. Inorganic components are composed of clay, limestone and titanium dioxide, which are papermaking additives. Paper ash is a fly ash or flooring material generated during the incineration process, and is a type of inorganic waste that remains after the combustion of organic matter. In addition, some incompletely burned organic components are contained in the combustion process. It is generated by incineration of paper sludge at about $750^{\circ} \mathrm{C}$. It can be used as a treatment method of industrial by-products because it can remove organic substances present in paper sludge and reduce the volume of waste. The incineration process causes the $\mathrm{CaCO} 3$ to undergo a calcination reaction to increase the content of $\mathrm{CaO}$, to make the crystal fine, to increase the specific surface area, and to increase the reactivity[4], [9]-[10].

\section{EXPERIMENTAL RESULTS AND ANALYSIS}

\section{A. $\mathbf{p H}$}

The $\mathrm{pH}$ of the formulation water is measured according to the type of alkali stimulants and the addition rate. Thereafter, the mixture was added to the compounding water, and the mixture was sealed so as not to evaporate, followed by a constant temperature and humidity (temperature $20 \pm 2{ }^{\circ} \mathrm{C}$, humidity $80 \pm 5 \%$ ). Fig 1 shows that the $\mathrm{pH}$ of the mixed water according to the type of alkali stimulants was measured. In the case of $\mathrm{NaOH}$ and $\mathrm{KOH}, \mathrm{pH}$ was slightly lower after the addition. Although the accuracy of the meter is unclear, the concentration of the water is likely to increase gradually as the measurement time increases and the $\mathrm{pH}$ concentration increases.

\section{B. Setting time}

The setting time of Fig 2 accelerated the activation of blast furnace slag according to the addition amount of $\mathrm{NaOH}$, $\mathrm{KOH}, \mathrm{Ca}(\mathrm{OH})_{2}$. In the case of $\mathrm{NaOH}$, the addition of $2.5 \%$ resulted in a reduction in the setting time of 502minutes and a reduction of the setting time of about $65 \%$ at the ending time of 134 minutes when $12.5 \%$ was added. The addition of $2.5 \%$ of $\mathrm{KOH}$ decreased the ending time from $456 \mathrm{~min}$ to $12.5 \%$, and the addition of $12.5 \%$ of $\mathrm{Ca}(\mathrm{OH})_{2}$ to the ending time of $139 \mathrm{~min}$. As the addition rate of alkali stimulants increased, the termination time was shortened. The incorporation of alkali stimulants above a certain level had little effect on the setting time.

\section{Compressive strength}

As shown in Fig. 3, the hardness of $\mathrm{NaOH}$ and $\mathrm{KOH}$ tended to decrease slightly as the addition rate increased. However, it was confirmed that the strength of long-term age was later developed. In addition, the strength of the matrix containing
$12.5 \% \mathrm{NaOH}$ was the highest and the $\mathrm{KOH}$ was the highest at $17.5 \%$. The stimulant addition rate of $7.5 \sim 17.5 \%$ showed similar strength and then the strength was increased with the stimulant addition ratio. As the amount of $\mathrm{NaOH}$ and $\mathrm{KOH}$ used increases in the non-mixing process, a large amount of bubbles are generated at the beginning of the mixing(contact with the compound water). In this case, since the mixing is maintained for a certain period of time, it is considered that the bubbles generated are released to the outside of the binder due to the expansion pressure, resulting in cracks and the like. On the other hand, the matrix using $\mathrm{Ca}(\mathrm{OH}) 2$ showed higher strength enhancement according to the long-term age than those using $\mathrm{NaOH}$ and $\mathrm{KOH}$ at each level. It is considered that this is due to the intensity of $\mathrm{Ca}(\mathrm{OH}) 2$ ionization. In addition, there are no visible cracks, and the amount of hydrogen gas generated in a large amount is very small, which does not seem to affect the strength.

\section{Density}

As shown in Fig. 4, the density of the matrix added with $\mathrm{KOH}$ was the lowest when the density was $22.5 \%$. The density of the matrix containing $2.5 \%$ of the stimulants was the lowest. The density reduction rate was lower than that of $\mathrm{NaOH}$ or $\mathrm{KOH}$. $\mathrm{NaOH}$ had the lowest density of $17.5 \%$ matrix. In the case of adding $\mathrm{NaOH}$, the generation time of bubbles occurred from the mixing process after the mixing water contact, and the amount of hydrogen gas was different according to the amount of addition. The addition of $\mathrm{KOH}$ showed similar tendency to that of $\mathrm{NaOH}$, and the period of bubble generation was similar. The binder with $\mathrm{Ca}(\mathrm{OH})_{2}$ added bubbles after the mixing process. The increase of the mass per unit volume due to the increase of the amount of $\mathrm{Ca}(\mathrm{OH})_{2}$ was judged to be unsuitable for the manufacture of lightweight matrix.

\section{E. Porosity}

Fig 5 shows the cross-sectional shape of the matrix according to the type of alkali stimulant, and confirmed the bubbles in the matrix. The number of pores overlapping the grid on the surface of the specimen was measured and expressed as the porosity by percentage. The total number of grids on the surface of the specimen was fixed to 600 .

\section{F. Pearson correlations analysis}

We used the program implemented by IBM SPSS Statistic to measure the correlation coefficient between the experimental data. It was performed the bivariate correlation analysis for each data. Reliability was set at $95 \%$ and Pearson correlation coefficient and P-value were tested. As known in Table 2 and 3, This is the analysis of correlation coefficient according to $\mathrm{NaOH}$ utilization. In Table 4 and 5, This is the correlation coefficient analysis according to the properties of the matrix using $\mathrm{KOH}$. As shown in Table 6 and 7, This is the correlation coefficient analysis of cured products using $\mathrm{Ca}(\mathrm{OH})_{2}$. 

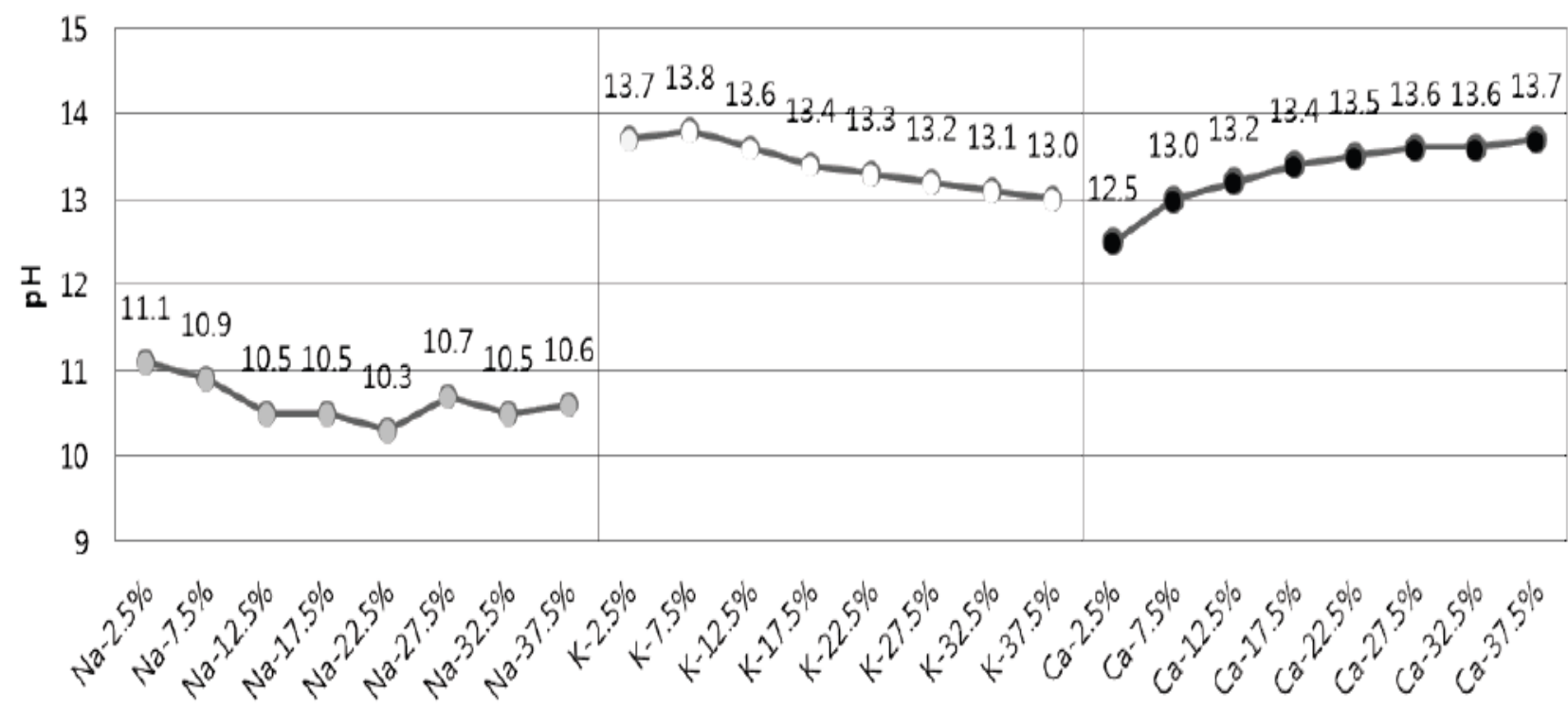

Fig 1. $\mathrm{pH}$ of formulation water

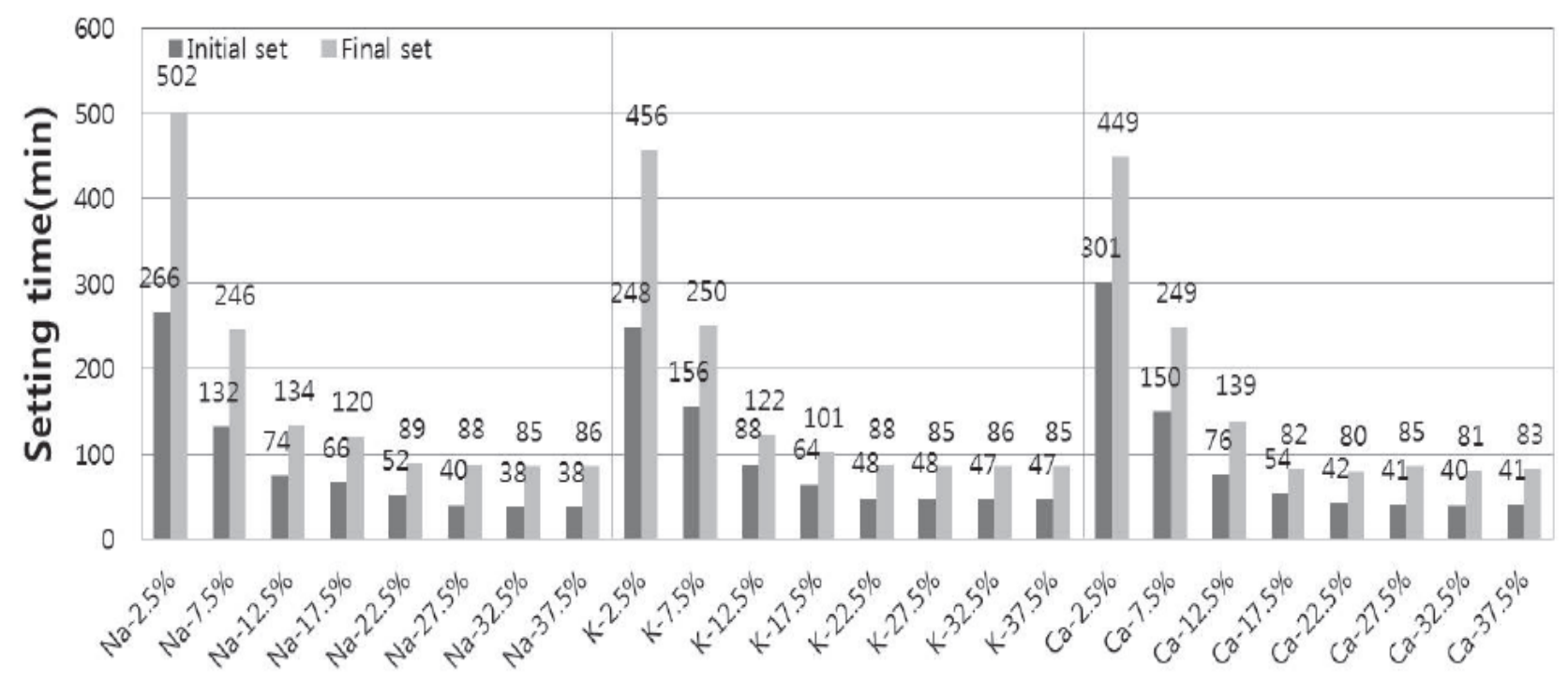

Fig 2. Setting time of paste
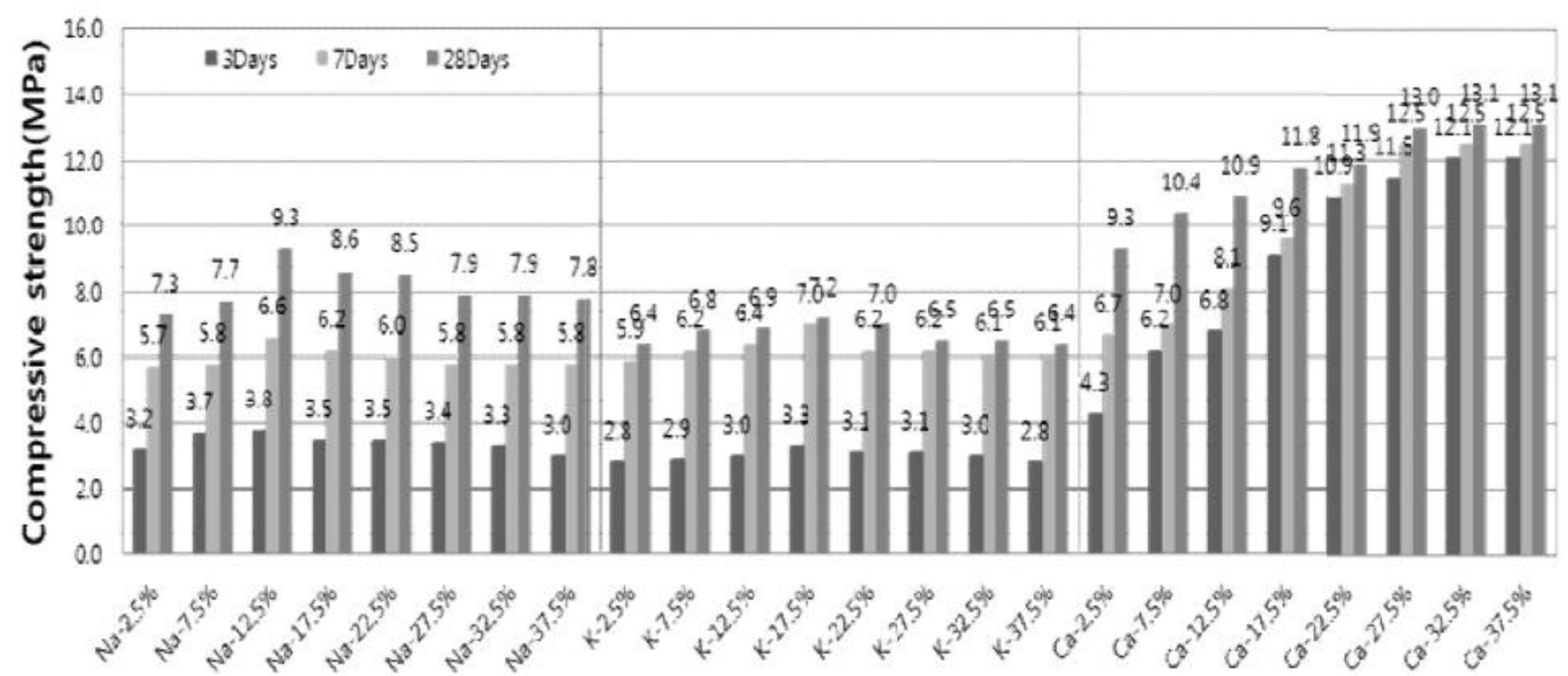

Fig 3. Compressive strength of matrix

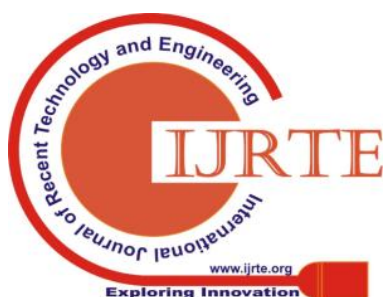


Properties of Lightweight Matrix according to Different Types of Alkali Stimulants

\begin{tabular}{|c|c|c|c|c|c|c|c|c|c|c|c|c|c|}
\hline & Plain & $\begin{array}{c}\text { N-N2S3 } \\
0.5 \%\end{array}$ & $\begin{array}{c}\mathrm{N}-\mathrm{N} 2 \mathrm{S3} \\
1.0 \%\end{array}$ & $\begin{array}{c}\text { N-N2S3 } \\
1.5 \%\end{array}$ & $\begin{array}{c}\text { N-N2S4 } \\
0.5 \%\end{array}$ & $\begin{array}{c}\mathrm{N}-\mathrm{N} 2 \mathrm{~S} 4 \\
1.0 \%\end{array}$ & $\begin{array}{c}\text { N-N2S4 } \\
1.5 \%\end{array}$ & $\begin{array}{c}\mathrm{N}-\mathrm{NC3} \\
0.5 \%\end{array}$ & $\begin{array}{c}\text { N-NC3 } \\
1.0 \%\end{array}$ & $\begin{array}{c}\text { N-NC3 } \\
1.5 \%\end{array}$ & $\begin{array}{c}\mathrm{N}-\mathrm{K} 2 \mathrm{S3} \\
0.5 \%\end{array}$ & $\begin{array}{c}\mathrm{N}-\mathrm{K} 2 \mathrm{S3} \\
1.0 \%\end{array}$ & $\begin{array}{c}\mathrm{N}-\mathrm{K} 2 \mathrm{S3} 3 \\
1.5 \%\end{array}$ \\
\hline 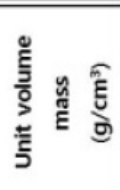 & $\begin{array}{c}1.90 \\
0\end{array}$ & 2.05 & 2.10 & $\stackrel{2.10}{-0}$ & 2.11 & 213 & $20^{3}$ & 1.98 & سمس & $\begin{array}{l}2.02 \\
-0\end{array}$ & $\begin{array}{c}2.00 \\
0\end{array}$ & ${ }^{2.01}$ & $\stackrel{2.02}{0}$ \\
\hline 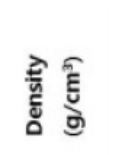 & $\begin{array}{c}1.14 \\
\circ\end{array}$ & 1.09 & ${ }^{1.09}$ & $\begin{array}{c}1.10 \\
-\end{array}$ & $\begin{array}{c}1.26 \\
0\end{array}$ & $\mathrm{~W}^{1.27}$ & $\begin{array}{l}1.27 \\
\longrightarrow\end{array}$ & 1.11 & ${ }^{1.12}$ & $\stackrel{1.12}{\longrightarrow}$ & $\begin{array}{c}1.18 \\
0\end{array}$ & ${ }_{-\infty}^{1.18}$ & مس \\
\hline 离施 & 40.00 & 46.83 & 48.10 & 47.62 & 40.28 & $\underset{\sim}{40.38}$ & $\stackrel{40.38}{\longrightarrow}$ & 43.94 & $\stackrel{44.28}{\longrightarrow}$ & $\stackrel{44.55}{\longrightarrow}$ & $\begin{array}{r}41.00 \\
\bullet\end{array}$ & $\stackrel{41.29}{\longrightarrow}$ & $\stackrel{39.11}{\longrightarrow}$ \\
\hline
\end{tabular}

Fig 4. Density of matrix

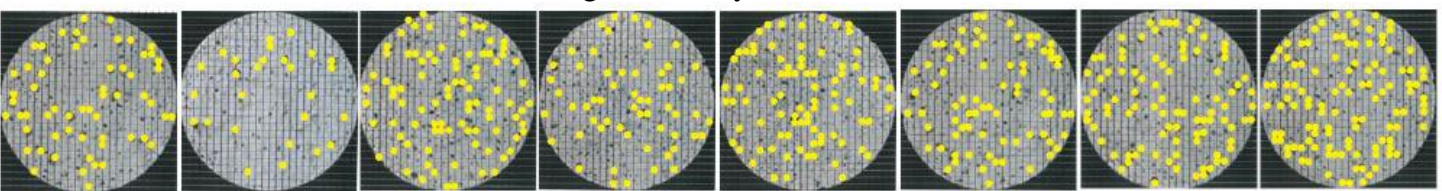

NaOH 2.5\%

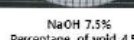

№OH $12.5 \%$

NoOH $17.5 \%$

NonOH 22.5\%
Percentage of void $16 \%$

NoOH $27.5 \%$

NoOH $32.5 \%$
Petrentage of void $16 \%$

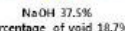
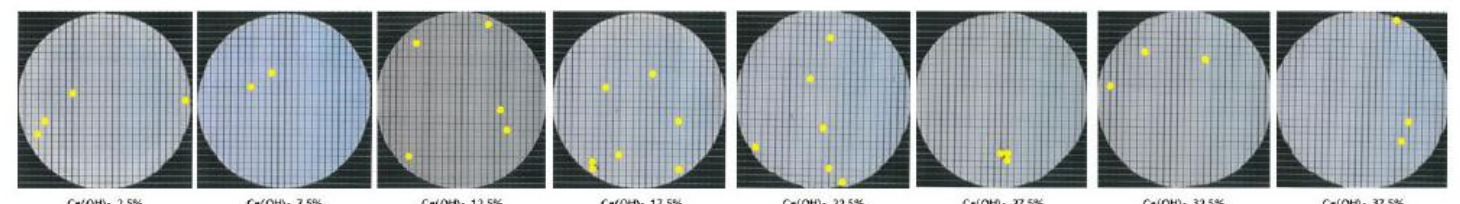

$\mathrm{Ca}(\mathrm{OH}))_{2} 2.5 \%$
Pectentoge of void $0.7 \%$

Cog(Ot) 2 2.5.5\%

Co(OHA) $27.5 \%$

$\mathrm{Ca}(\mathrm{OH}) \mathrm{C}_{2} 32.5 \%$

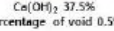

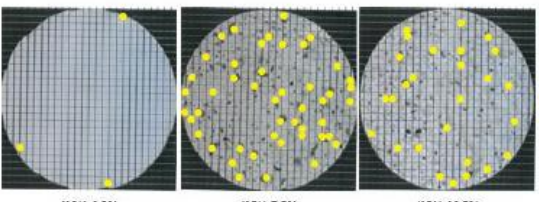

KOH $2.5 \%$

KOH $7.5 \%$
Percentage of void $7.8 \%$

KOH $12.5 \%$
Percentage of void $4.5 \%$
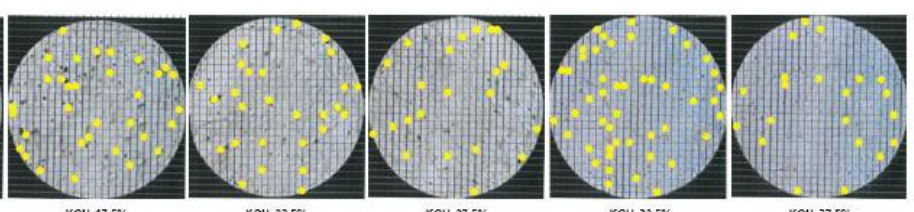

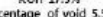

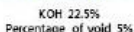

KOH $27.5 \%$
Percentage of void $3.7 \%$

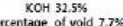

KoH $37.5 \%$
Percentage of void $3.5 \%$

Fig 5. Porosity of matrix

Table 2. Correlation according to kinds of alkali stimulants $(\mathrm{NaOH})$

\begin{tabular}{|l|c|c|c|}
\hline \multicolumn{4}{|c|}{ Descriptive statistics } \\
\hline & Mean & Std. Deviation & $\mathrm{N}$ \\
\hline $\mathrm{pH}$ & 10.64 & 0.26 & 8 \\
\hline Compressive strength & 8.13 & 0.63 & 8 \\
\hline Percentage of void & 12.51 & 5.41 & 8 \\
\hline Density & 1.19 & 0.05 & 8 \\
\hline Setting time & 168.75 & 145.09 & 8 \\
\hline
\end{tabular}

Table 3. Correlation analysis according to kinds of alkali stimulants $(\mathrm{NaOH})$

\begin{tabular}{|c|l|c|c|c|c|c|}
\hline \multicolumn{2}{|c|}{ Correlations } \\
\hline \multirow{2}{*}{$\mathrm{pH}$} & Pearson correlation & 1 & $-0.72^{*}$ & -0.60 & 0.07 & $0.86^{* *}$ \\
\cline { 2 - 6 } & Sig. (2-tailed) & & 0.04 & 0.11 & 0.88 & 0.01 \\
\cline { 2 - 6 } & $\begin{array}{l}\text { Sum of squares and } \\
\text { cross-products }\end{array}$ & 0.46 & -0.82 & -5.86 & 0.01 & 222.35 \\
\cline { 2 - 7 } & Covariance & 0.07 & -0.12 & -0.84 & 0.00 & 31.77 \\
\cline { 2 - 7 } & $\mathrm{N}$ & 8 & 8 & 8 & 8 & 8 \\
\hline *. Correlation is significant at the 0.05 level(2-tailed). \\
\hline **. Correlation is significant at the 0.01 level(2-tailed).
\end{tabular}


Table 4. Correlation according to kinds of alkali stimulants( $\mathrm{KOH})$

\begin{tabular}{|c|c|c|c|}
\hline \multicolumn{4}{|c|}{ Descriptive statistics } \\
\hline Mean & Std. & Deviation & $\mathrm{N}$ \\
\hline $\mathrm{pH}$ & 13.39 & 0.29 & 8 \\
\hline Compressive strength & 6.71 & 0.30 & 8 \\
\hline Percentage of void & 4.78 & 2.37 & 8 \\
\hline Density & 1.26 & 0.13 & 8 \\
\hline Setting time & 159.13 & 132.31 & 8 \\
\hline
\end{tabular}

Table 5. Correlation analysis according to kinds of alkali stimulants( $\mathrm{KOH})$

\begin{tabular}{|c|c|c|c|c|c|c|}
\hline \multicolumn{7}{|c|}{ Correlations } \\
\hline & & $\mathrm{pH}$ & $\begin{array}{c}\text { Compressive } \\
\text { strength }\end{array}$ & Percentage of void & Density & Setting time \\
\hline \multirow[t]{5}{*}{$\mathrm{pH}$} & Pearson correlation & 1 & 0.29 & -0.06 & 0.42 & $0.71 *$ \\
\hline & Sig.(2-tailed) & & 0.48 & 0.88 & 0.30 & 0.05 \\
\hline & Sum of squares and cross-products & 0.59 & 0.18 & -0.30 & 0.11 & 191.51 \\
\hline & Covariance & 0.08 & 0.03 & -0.04 & 0.02 & 27.36 \\
\hline & $\mathrm{N}$ & 8 & 8 & 8 & 8 & 8 \\
\hline
\end{tabular}

Table 6: Correlation according to kinds of alkali stimulants $\left(\mathrm{Ca}(\mathrm{OH})_{2}\right)$

\begin{tabular}{|l|c|c|c|}
\hline \multicolumn{3}{|c|}{ Descriptive statistics } \\
\hline & Mean & $\begin{array}{c}\text { Std. } \\
\text { Deviation }\end{array}$ & $\mathrm{N}$ \\
\hline $\mathrm{pH}$ & 1.83 & 0.04 & 8 \\
\hline Compressive strength & 156.00 & 132.04 & 8 \\
\hline Percentage of void & 13.31 & 0.40 & 8 \\
\hline Density & 11.69 & 1.40 & 8 \\
\hline Setting time & 0.69 & 0.30 & 8 \\
\hline
\end{tabular}

Table 7: Correlation analysis according to kinds of alkali stimulants $\left(\mathrm{Ca}(\mathrm{OH})_{2}\right)$

\begin{tabular}{|c|c|c|c|c|c|c|}
\hline \multicolumn{7}{|c|}{ Correlations } \\
\hline & & $\mathrm{pH}$ & $\begin{array}{c}\text { Compressive } \\
\text { strength }\end{array}$ & Percentage of void & Density & Setting time \\
\hline \multirow[t]{5}{*}{$\mathrm{pH}$} & Pearson correlation & 1 & -0.70 & $0.86^{* *}$ & $0.95 * *$ & -0.24 \\
\hline & Sig.(2-tailed) & & 0.05 & 0.01 & 0.00 & 0.57 \\
\hline & Sum of squares and cross-products & 0.01 & -28.13 & 0.11 & 0.40 & -0.02 \\
\hline & Covariance & 0.00 & -4.02 & 0.02 & 0.06 & -0.00 \\
\hline & $\mathrm{N}$ & 8 & 8 & 8 & 8 & 8 \\
\hline
\end{tabular}

\section{CONCLUSION}

In this study, we have developed a matrix which can be used as a core of lightweight composite panel using inorganic materials to prevent harmful gas generated by burning existing lightweight composite panel in case of fire. As a result of $\mathrm{pH}$ measurement, irrespective of kinds of alkali stimulants, all showed high alkalinity of $\mathrm{pH} 10$ or higher. As a result of the measurement of the setting time, activation of blast furnace slag was promoted according to the amount of alkali stimulant added, resulting in shortening of the final result. As a result of the compressive strength measurement, the matrix containing $\mathrm{NaOH}$ and $\mathrm{KOH}$ was found to exhibit a long-term strength development with increasing the addition ratio. $\mathrm{Ca}(\mathrm{OH})_{2}$ exhibited long-term intensities and the results were dependent on the degree of ionization of $\mathrm{OH}$ groups. As a result of the density measurement, the density of the matrix containing $\mathrm{NaOH}$ was the lowest. As a result of measuring porosity of the matrix, the bubble generation rate in the matrix was increased as the addition rate of the alkali stimulant increased.

\section{REFERENCES}

1. Sandwich panels and fire hazards, 2018. Retrieved from http://blog.daum.net/belief 137/17433708.

2. So, T,S. A Basic Study on Development of Legal Requirement for Fire Proofing of External Composite Panel and Joints. Masters dissertation. Tongmyong University, Busan, Korea. 2014.

3. Lee, K.P. Non-cement Eco-friendly Lightweight Composite Panel Properties of Utilizing the Waste Resources. Masters dissertation. Hanbat University, Daejeon, Korea. 2012.

4. Kim, Y.M. Foaming Properties of Lightweight Matrix using Paper Ash based on Blast Furnace Slag. Masters dissertation. Hanbat University, Daejeon, Korea. 2015. 
5. Lee, S.S. Study on the Strength and Flowing Properties of Cementless Type Eco-friendly Inorganic Composites by Using Alkali Accelerator. Journal of the Architectural Institute of Korea Structure \& Construction, 26(5), 67-74. http://www.dbpia.co.kr/Journal/ArticleDetail/NODE01445079\#.

6. Park, S.K., Kim, Y.M., \& Lee, S.S. Characteristic of Non Cement Matrix using Alkali Accelerator and Paper Ash. The Korea Institute For Structural Maintenance and Inspection, 13(10), 344-345. 2013. http://db.koreascholar.com/Article?code=2 92365.

7. Kim, Y.S., Moon, D.Y., \& Lee, D.W. An Experimental Study on Alkali-Silica Reaction of Alkali-Activated Ground Granulated Blast Furnace Slag Mortars. Journal of the korea institute of building construction, $\quad 11(4), \quad 345-325 . \quad 2011$ http://www.riss.kr/link?id=A82659252.

8. Lee, S.H., \& Lee, S.S. Density and Strength Properties of Non-Portland Cement Lightweight Matrix according to Mixing Ratio of Alkali Activator. Journal of the Construction and Environment Research $\begin{array}{lll}\text { Institute, } & 10(1), & 185-192 .\end{array}$ https://www.kci.go.kr/kciportal/ci/sereArticleSearch/ciSereArtiView.k ci?sereArticleSearchBean.artiId=ART002022147.

9. Kim, W.J., Lee, S.H., \& Lee, S.S. The Density and Strength Properties According to the Mixing Time of the Lightweight Composites using the Paper Ash. Korea concrete institute, 15(5), 657-658. 2015. http://www.dbpia.co.kr/Journal/ArticleDetail/ NODE06358692.

10. Kim, H.T. Evaluation on the Application Properties of Lightweight Composite Panel Using Low Melting Modified Sulfur (Doctoral dissertation). Hanbat University, Daejeon, Korea. 2018.

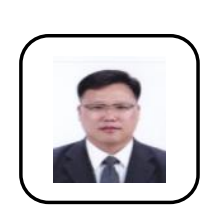

\section{AUTHORS PROFILE}

Won-Jong, Kim Doctor, Department of Architectural Engineering, Hanbat National University, Daejeon, Korea.

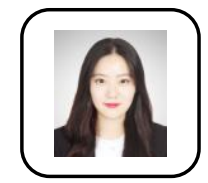

Su-Jeong, Pyeon Doctoral course, Department of Architectural Engineering, Chungnam National University, Daejeon, Korea.

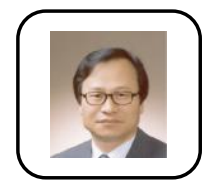

Song-Ha, Young Professor, Department of Architectural Engineering, Hanbat National University, Daejeon, Korea.

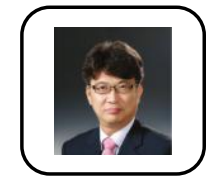

Sang-Soo, Lee Professor, Department of Architectura Engineering, Hanbat National University, Daejeon, Korea. 